\title{
CONCEPT
}

\section{Time for an Alternative Perspective: The Eternal Problem of Supply and Quality of Anti Snake Venom in the Developing World-_It's the Economy, Stupid"}

\author{
Ian D. Simpson, BSc, PG (Dip) \\ From the Pakistan Medical Research Council, Islamabad, Pakistan; and the West Bengal Government Snakebite Taskforce, Kolkata, India.
}

\begin{abstract}
The "crisis in anti snake venom supply" has been an enduring problem. Despite the frequency with which it appears in the literature, it remains unquantified and an enigma. If there is a serious shortage of anti snake venom (ASV), why has this not been resolved? Anti snake venoms are produced, and yet many suppliers are described as leaving the market. There appears to be a problem in the call for highly effective, high-quality, and cheap anti venoms that contributes to this result of suppliers leaving the market. Private companies are tasked with achieving adequate shareholder returns and by doing so ensure continued supply. Efforts should therefore target a means of lowering production cost by introducing whole immunoglobulin $\mathrm{G}(\mathrm{IgG})$ antivenoms with greater antibody yields, reducing the drive to eliminate adverse reactions, for which there are other more cost-effective treatments, as well as a means of introducing good manufacturing processes, with care based on demonstrable need. In order to ensure sustainability of supply, a private company supplier providing a whole IgG antivenom that effectively neutralizes venom is the most credible option. The need for ASV in areas of shortage mandates the need for clear decisions regarding the type of ASV and the recognition that the market requires acceptable returns for producers if supply is to be sustainable. This paper reviews the economic realities of ASV production and suggests a pragmatic, sustainable approach to the problem of supplying ASV to developing countries.
\end{abstract}

Key words: snakebite, snake envenomation, antivenom, policy maker, antivenom costs, developing world

\section{Introduction}

Bill Clinton's famous election battle cry of "It's the economy, stupid" during the 1992 US presidential elections was focused and pertinent for the situation that existed at that time in the United States. Despite attempts by the incumbent president to direct attention away from the economic reality toward some ethereal ideal, Clinton correctly deduced that the economic reality was primary. The message was very clear: all activities are ultimately set within the economic environment, and the rules operating there, however inconvenient or difficult for interest groups, are nevertheless rules. Despite the assumption that the economic system is a free market of competing financial and corporate institutions, there are

No grants were received in connection with this paper.

Corresponding author: Ian D. Simpson, Kooran House, Nayathode, Kerala 683572, India (e-mail: iandsimpson@gmail.com). underlying precepts that determine how companies operate.

The provision of anti snake venom (ASV) has been a long and enduring problem. Many countries in the developing world, where the vast majority of snakebite mortality and morbidity is incurred, are described as having a shortage of ASV. ${ }^{1-11}$ This is undoubtedly an important situation, but it is also a complex one. ${ }^{12}$

The actual level of any shortage has been poorly defined, but where shortages are established the requirement for ASV is obvious. Yet successful and sustainable supplies in certain areas remain out of reach. ${ }^{1-11}$ The trend in the ASV market sector has been for government producers to outsource production to private companies, who then later withdraw from ASV production on the grounds that it offers poor economic return. ${ }^{13}$

If economically rational, private companies with an objective to make returns for their shareholders; unsatisfied demand ${ }^{1,3,4,6,8-11}$; and ASV products are all pre- 
sent, ${ }^{14-17}$ then the following conundrum exists: Why have these not combined to provide a marketing mix that solves the ASV problem? There appears to be a barrier in the type of product being requested, a barrier that is undermining what would appear to be the presence of all the necessary conditions to provide sustainable ASV supplies. This paper seeks to explain the conundrum and to indicate potential options by which the problem could be resolved.

\section{Private production and shareholder interests}

Private pharmaceutical companies are owned by shareholders, who in current times are principally large financial institutions, such as insurance and pension companies. Their objective, whether they are small shareholders or institutions, is to achieve at least average, but preferably above-average, returns on their investment. This level of return is usually expressed as the amount you receive from the institution as a percentage of what you invest in the form of share capital. In that sense the level of return is exactly the same as bank interest. In corporate terms this is referred to by a number of terms, but the simplest and most common is return on assets (ROA). It is expressed as follows:

$$
\text { ROA }=\frac{\text { Profit Before Tax (PBT) }}{\text { Assets }}
$$

In this model PBT represents profit retained by the company after deducting all costs of production and overhead costs from the revenue earned from selling product. Assets represent the shareholder's equity or investment in the business. The underlying assumption is that shareholders invest cash, which the company in turn uses to buy assets to produce product and thus earn revenue. Return on assets is crucial as it is used to attract investments in the company. Shareholders are obviously interested in investing in companies that provide a high ROA and particularly in ones that deliver higher ROA than their competitors in the same market segment. Each market segment-for example, pharmaceutical companies - will have a known and acceptable level of return that will be the overall market expectation of performance, which in this case is $20 \% .^{18}$ If a company performs below the market expectation then adverse consequences in terms of shareholder willingness to invest will occur, which will be heavily resisted by all corporate entities.

\section{Key submeasures and corporate strategy}

In order to manage ROA, stakeholders (managers, shareholders, and the market) use 2 key measures to ensure that both parts of the ROA equation are being managed effectively. These 2 ratios are also important to understanding corporate strategy.

In order to understand the PBT side of the ratio, a measure called return on sale (ROS) is employed. This is expressed as follows:

$$
\operatorname{ROS}=\frac{\text { PBT }}{\text { Revenue }} \times 100
$$

Return on sale expresses how much profit the company retains, as a percentage of revenue, after deducting all the costs of producing the product and the overhead costs for management and infrastructure, etc. This ratio shows how efficient the company is at retaining profit, and from a shareholder perspective, the more profit retained the more the shareholders will receive. It is sometimes called the profitability ratio.

The next ratio, asset turnover (ATO), or "Turns" in the United States, is geared to reassuring shareholders that their investments or assets are safe, and this is indicated by how many times the asset base is covered by revenue earned by the company. The assumption is that the more revenue earned, the more likely the shareholders will be able to salvage their assets should the company fail and go into liquidation. It is expressed as a whole number, thus:

$$
\mathrm{ATO}=\frac{\text { Revenue }}{\text { Assets }}
$$

For example, Pharmaceutical Company A has an asset base of $\$ 500$ and a revenue of $\$ 1000$. Its ATO would be 2 .

If we now schedule out all 3 ratios, ROS, ATO, and ROA, we will see the essence of corporate strategy:

$$
\left[\frac{\text { PBT }}{\text { Revenue }}(\times 100)\right] \times \frac{\text { Revenue }}{\text { Assets }}=\frac{\text { PBT }}{\text { Assets }}
$$

Using the example and assuming a profit figure of $\$ 100$, then,

$$
\left[\frac{100}{1000}(\times 100)\right] \times \frac{1000}{500}=20 \% \mathrm{ROA}
$$

The relationship between these measures of performance is directly mathematical:

$$
\text { ROS } \times \text { ATO }=\text { ROA. }
$$

The market determines the required level of return for each market segment in terms of ROA, and each company within the segment will strive to achieve at least that level of ROA, or, preferably, a higher level of ROA. The expected level of return for each sector is dynamic and is based on competing with the returns from alter- 
native investment opportunities available to investors, for example, commodities such as gold.

However, the means to achieve a target ROA are variable, as the above equation shows, and will often depend on the structure and nature of the business. It is possible to deliver a very low ROS by offering a cheap, low-margin product with, for example, an ROS of $2 \%$, but that means you have to deliver a high ATO of 10 turns to deliver an acceptable shareholder return of $20 \%$.

A company is either a high-ROS (or premium-priced) company or it is a high-ATO company like Wal-Mart and offers a low-cost product but sells vast quantities. The famous dictum "stack it high, sell it cheap" captures this latter philosophy.

\section{The twin approaches to success}

Corporate entities will therefore use either a ROS or an ATO approach to achieve the level of ROA demanded by the market sector. This leads them to adopt completely different approaches in terms of how they manage and operate their business.

\section{Return on sale company fundamentals}

In a high-ROS business, the level of profitability must be kept high and protected from reduction. Companies with an ROS business model seek to establish pricing for a product, calculated by taking the costs involved in production (both direct costs, such as labor, and indirect costs, such as advertising, promotion [eg, sponsoring conferences for snakebite experts to attend], and research and development) and multiplying these by a factor to give the required return on sale. For example, if total costs are $\$ 500000$ and a return of $20 \%$ ROS are required, the factor is 1.25 , giving a revenue figure of $\$ 625000$. The revenue figure divided by product units determines unit cost to consumer. These companies want to keep costs tightly controlled, as increasing costs will reduce ROS. They are concerned about the asset base because it generates more cost as it is depreciated or used up in the production process. They cannot reduce ROS because they need it for delivering ROA and they need to invest in new products. They will sell you a high-quality product, but they cannot sell it to you cheap.

\section{Asset turnover company fundamentals}

Asset turnover companies, on the other hand, are very concerned with revenue-it must be maximized and grow in order to drive ATO upwards. They require accurate forecasts of how much revenue is possible in or- der to assess the likely level of ROA. Assets such as equipment are reduced to as low a level as possible in order to maximize ATO. The lower the asset number, the higher the ATO. Companies like Wal-Mart seek to directly match stock orders from suppliers to match what they have sold that day so that stock (another asset) is kept at the lowest level possible. They are less concerned with profit or ROS because they are not going to generate high ROA on this side of the equation. They are looking for mass sales on a very low asset base, and they are looking for a basic, mass-market product. They will sell it to you cheap, however, because they need the volume of sales.

\section{The economics of ASV production}

The production of ASV is a capital-intensive businessland must be secured for the grazing of the animals, and buildings and equipment established for the production process. Once there is a high asset base, either revenue has to be very high to deliver a high number of asset turns or the company has to adopt a high-ROS strategy and ensure profit is high in order to generate a high ROA.

Using a practical example, the asset base on a new production facility in Pakistan is approximately $\$ 2.25$ million, and the unit price per vial of ASV is approximately $\$ 10 .{ }^{19}$ In order to generate an asset turns performance of 1 it would require the plant to produce 225000 vials of ASV, roughly twice the national requirement. To produce the total national requirement would generate an asset turns number of 0.5 , which would require an ROS of $40 \%$ to deliver $20 \%$ ROA. This would imply the requirement to increase unit price to drive ROS to $40 \%$, which, using the current economics, equates to a $36 \%$ price increase.

The other alternative is to increase volume and find other potential markets. Is the provision of ASV a business with high product volume and the ability to increase that volume? The short answer is that it is very unlikely and would probably involve the risk of entering nondomestic markets as well as reliance on estimates of demand that have known weaknesses, such as the imprecise estimates of morbidity and mortality related to snakebite.

It has been proposed that the ASV volume requirement for Africa would ensure the economic viability of a manufacturer providing ASV. ${ }^{11}$ However, current epidemiology numbers for envenomations in both Africa and elsewhere are highly suspect, based largely on a few isolated studies, factored across broad rural populations. ${ }^{8,20}$ These numbers are very unreliable and are likely to represent an overestimate. In West Bengal, India, 
a lower-than-predicted incidence of envenoming and a positive impact of a rational treatment protocol have been observed (I.D.S., unpublished data, 2007). If current volume in Africa is sufficient to generate the necessary volume of sales, why has the current multinational provider not been able to satisfy demand at a low cost? The reality is that even with the current probably overestimated demand, the requirement to generate adequate returns on a high asset base business ensures that the current supply must be sold at high cost, rendering it unaffordable to most African countries.

Volume-based approaches, and, therefore, the ATO model, do not seem to be a solution. This example leads to the most probable conclusion that the provision of ASV is likely to be a business model based on return on sale or profitability rather than on high levels of revenue or low levels of assets delivering high ATO.

\section{Noneconomic return-based models of ASV production}

The key objective is successful long-term production, which maintains consistent supply at levels sufficient to meet proven demand and that minimizes cost to the customer. There are a number of business structures that could provide this supply. If we are seeking to provide the lowest cost ASV possible but desire to maintain the highest level of quality, the element that could be removed is the profit margin.

Anti snake venom could be produced by government organizations that are not subject to shareholder demands for return on investment, as the model in Mexico or Brazil. ${ }^{21,22}$ Alternatively, governments could subsidize production costs, thus enabling suppliers to sell at a below-true market rate. ${ }^{21}$ Anti snake venom could therefore be sold at or near cost. This appears to be the ideal solution. In a number of countries, for example, India and Pakistan, a number of state or central government organizations produce ASV and supply it to the market.

However, a cursory examination of market pricing reveals that the government-produced ASV does not always offer pricing that is below market rates and in countries such as India is above the level offered by private producers. This results from inefficiencies in production that are attributable to low investment and funding pressure from governments with competing priorities. Proponents of the government production model accept that shortages occur and that countries must group together to reach production levels sufficient to generate economic production. ${ }^{22}$

A further issue arises in the government model with regard to product quality and research into newer ASVs.
Improvements in quality and research and development require governments to fund infrastructure elements in the producer. In most developing world countries, these funds are simply not available. For example, in India, product support literature has remained unchanged since the 1940s, and this is due to the pressure to maintain the status quo and to not invest in activities other than production. ${ }^{23}$

With regard to long-term consistency of supply, government-funded agencies are subject to political priorities for funds. When considered alongside transport infrastructure, basic amenity improvements, and basic health care (eg, ensuring that all hospitals and clinics are staffed by the required number of doctors), the production of ASV will always remain a tenuous proposition. It is interesting that a government supplier in India has had to purchase lyophilized ASV from a private manufacturer and resell it under its own label as a result of an inability to secure additional production capability (unpublished data). Other authors have remarked on the trend for government producers to outsource production to private enterprises, presumably because ASV production is not a priority or, more likely, because the private sector approach is seen as more efficient. ${ }^{13}$

In some countries government production has undoubtedly worked; however, this production tends to be designed for domestic consumption. Once a national government considers supplying ASV to other countries a number of potential questions arise that require resolution:

- Do they provide ASV to other countries at cost or will a profit level be required? If it is required, then will the additional volume ensure that ATO can be increased and that the product will thus maintain a low cost for the purchaser?

- Will the new target market have snake species that are within the experience and capability of the current producer?

- Where does the production infrastructure reside and what will be the cost impacts of transportation of the end product?

- How sustainable will such production be? Governmental priorities change, and for a country with a high incidence of snakebite to be reliant on imported ASV may well stimulate local production. Once the original source country's production is dependent on other markets for its economic sustainability, a level of risk and potential instability is introduced.

Questions such as these will need careful consideration before the government model can be relied upon to produce multicountry solutions involving nonindige- 
nous species in a market structure in which corporate expertise predominates.

A possible alternative to governmental provision of ASV at cost price is that private companies could provide ASV at a price that gives a lower level of return than do other products in its portfolio. For example, could a major pharmaceutical company "subsidize" ASV, as it is such a vital commodity but does not provide adequate levels of return? The grim economic reality is that companies are responsible for shareholder funds on a macro level. The entity as a whole has to provide adequate returns to shareholders. Most companies are segmented into a number of product categories, each of which is tasked with providing adequate returns. Investment in each segment is determined by contribution to the entity as a whole. Non-ASV segments will simply advance and will succeed in the face of the argument against directing funds to ASV production when a higher return can be achieved with an alternative product. Long-term supply and investment in ASV is thus at serious risk. ${ }^{6}$

In summary, therefore, neither the government nor subsidized private alternative business structures look likely to provide a long-term, stable supply of cheap and appropriate ASV.

\section{An alternative model of ASV production}

To propose a new model of ASV supply it is necessary to address some of the key stated requirements of ASV made by advocates who propose more high-quality production. ${ }^{11}$ These requirements include the following:

- The ASV must be of high quality, usually expressed as generating very low levels of adverse reactions (ie, anaphylactoid or pyrogenic reactions);

- The ASV must have high effectiveness in terms of its capability to neutralize venom; and

- The ASV must carry a low cost.

There can be little doubt that the final 2 requirements are fundamental. Anti snake venom must be effective at neutralizing venom, and, since snakebite is almost exclusively a major issue in developing countries, costs must be minimized in order to deliver affordability.

\section{Quality and adverse reactions}

There are, however, serious concerns about the first of the 3 requirements and how to effectively address it. Considerable attention is given in the literature to the problem of adverse reactions to ASV. Reaction levels of $80 \%$ are quoted, and some ASVs have a particular reputation for "causing high levels of reaction." $24-26$

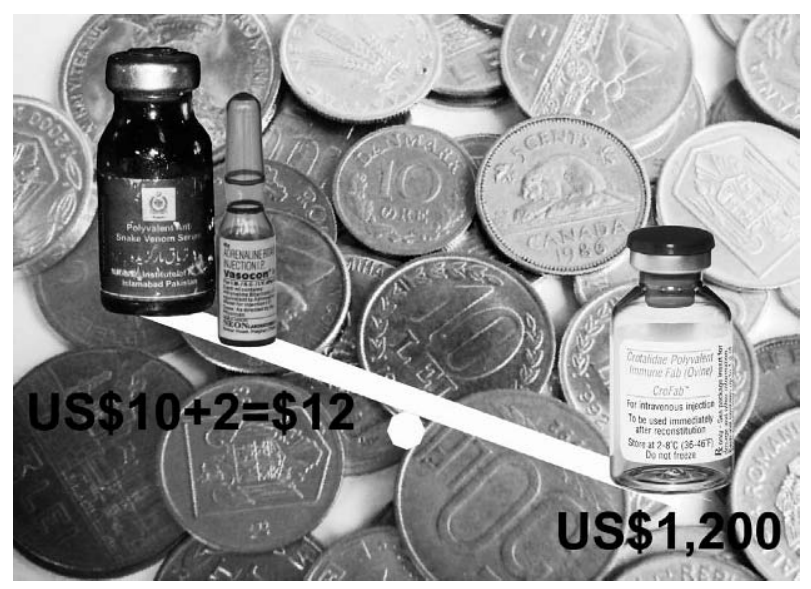

Figure. Comparison of costs involved in handling anti snake venom (ASV) reactions reactively and proactively.

While there is undoubtedly a requirement for drugs to be as safe as possible, drugs are rarely 'safe' if safe is defined as 'risk free.' The key points are the rate of these adverse reactions and how many are actually life threatening (compared to the risk associated with having no ASV available). ${ }^{27,28}$ Can these adverse reactions be simply dealt with by doctors in all environments, and what is the additional cost associated with reducing them compared with treating them?

These questions have been largely unaddressed for a considerable time period, and yet the assumptions concerning these questions are driving policy., ${ }^{9,26,29}$ For example, Indian ASV costs approximately US $\$ 10$ per vial, US ASV approximately US $\$ 1200$ per vial, and Australian ASV approximately US $\$ 1000$ per vial. In India, the costs of successful and effective treatment for an adverse reaction, with readily available intramuscular adrenaline and steroids, are approximately US $\$ 2 !^{130-34}$ There is, therefore, an effective treatment that is readily available and inexpensive that reduces the need to improve quality without demonstrable need. From the health care budgetary perspective the most effective method of managing adverse reactions may not involve burdening the manufacturer with additional costs that will be passed on to the purchaser of the ASV, but rather using inexpensive drugs that are already available (Figure).

The call for raising ASV quality to levels in developed world countries clearly makes no sense and could have a catastrophic effect on developing countries' health care budgets. The level of increased quality and the increased costs necessary to produce such ASV has been called into question by other authors. ${ }^{12,35}$ Further evidence of this can be found in Papua New Guinea, where, despite the frequent claims of an ASV shortage, the actual shortage is one of money, as Australian ASV 
is readily available but simply is not affordable as a result of its high cost. ${ }^{10,36}$

This is particularly relevant in the current environment of good manufacturing processes (GMP). There is little dispute that those manufacturers producing substandard or dangerous medications should be eliminated. However, the use of GMP may not be the answer to this problem, and it carries with it major downsides. First, GMP comes at a cost - the cost of a company implementing, cost of compliance auditing, cost of company time in obtaining the required certification, and all the costs that normally accompany certification in the developing world. All of these costs will carry with them a level of profit to maintain acceptable returns, and consumers will ultimately bear the cost. ${ }^{21}$

Second, in reality these standards rarely prevent the activity of the target companies, who will continue to produce substandard medications until they are prosecuted for the consequences. Such standards, by the very nature of the developing world environment, simply increase costs for the good producers and are ignored by the bad. There has been a recent report of a company with GMP standards, certified by the World Health Organization, that provided an ineffective ASV to the African market, hardly a resounding demonstration of the effectiveness of GMP. ${ }^{37}$ It is difficult not to draw the conclusion that in cases such as these, in which an ineffective ASV results in high risk/high wastage, GMP and the costs associated with achieving the certification have simply resulted in a higher cost of purchasing an ineffective ASV, without providing any greater degree of protection. ${ }^{38}$ Mandating the certification for good producers without demonstrable need will simply render the ASV situation worse by making ASV more unaffordable. This in itself will encourage the bad suppliers to provide more product, as their revenue will increase to fill the new shortfall.

\section{How to reduce cost}

The problem of how to reduce cost to the lowest level is still paramount. Developing countries have limited funds and many competing priorities, and production companies need to maintain adequate returns if they are to survive in the long term. We have seen that companies take cost and multiply the figure by a factor required to deliver acceptable market returns. We cannot change the factor, so we must reduce the costs of production. The cost base, however, will contain a large element of fixed costs, such as equipment to produce the ASV and the staff required to maintain the animals. ${ }^{22}$ Economies must be sought elsewhere.

\section{Costs and yield}

One method of reducing unit cost is to improve the yield of ASV on the current cost base. If more ASV can be produced on the current cost base, then the individual unit cost will be much lower. Recent research has shown that whole immunoglobulin $\mathrm{G}$ ( $\mathrm{IgG}$ ) ASV provides a much higher yield of antibodies than the current pepsin or papain digested ASVs. ${ }^{22}$ The yield of antibodies using caprylic acid precipitation is approximately $60 \%$, whereas the yield following pepsin digestion and ammonium sulfate fractionation is approximately $30 \% .^{22}$ This has an immediate and obvious effect on the cost base. While reducing the pepsin digestion phase has a small impact on direct costs of production in terms of costs contributed by this element, it has a tremendous impact on efficiency of output. Historically, the pursuit of improved quality, in terms of reduced reactions, has dictated that the Fc fragment has been the cause of the adverse reaction and that elimination of that fragment should be paramount. Improving purification processes has been targeted at eliminating this fragment, and costs have risen.

Whole IgG ASVs were not regarded as safe as a result of the risk associated with not eliminating the Fc fragment. The majority of studies, however, have established that whole $\operatorname{IgG}$ ASVs, particularly those that use the latest methods of caprylic acid precipitation, provide no greater risk of adverse reactions than do their pepsin and papain digested counterparts. ${ }^{17,39-44}$ In terms of reduction in antibodies in order to prevent adverse reaction, pepsin digestion to eliminate the Fc fragment does not seem justified. A significant reduction in the level of reactions has not been proved in all cases. The costs to treat adverse reactions to ASV are low compared to the major financial impact of trying to produce products with less risk.

\section{Potential path forward}

It is now possible to posit a potential solution to the initial conundrum of how to establish a marketing mix that provides a solution to ASV shortages. In so doing, a clear distinction must be made between "effectiveness" (ie, the ability to neutralize the target venom) and "quality," the level of life-threatening adverse reactions. These terms are sometimes used interchangeably, and this only complicates the debate. ${ }^{37}$

\section{Anti snake venom market provider}

The best business model is one that provides long-term sustainability to reverse the trend of decline in market 
providers. Currently the most effective structure is one provided by a private company with an ROS business model that makes acceptable returns and is thus incented to remain in the market. Health care providers must accept the need for companies to provide adequate shareholder returns that are specified by the market. It makes no sense to argue for ASV priced at levels below those required to deliver adequate returns and thus long-term sustainability. Provision of ASV by government organizations has a mixed success rate and has not proven capable of providing large-scale multicountry solutions.

\section{The ASV product}

The ASV should effectively neutralize the target venom and should not produce significant life-threatening reactions. No additional funding should be used to reduce the current level of reactions in effective products, as alternative and efficacious treatments, such as adrenaline, with very low cost render such improvements cost ineffective and are contrary to the philosophy of minimizing cost of treatment.

The ASV should preferably be a whole IgG antibody, as this provides the best economics for acceptable returns and provides a safety profile comparable to that associated with pepsin digested ASVs. Initial trial testing should establish its effectiveness in neutralizing venom and low levels of life-threatening reactions when treated early with adrenaline. No attempt should be made to impose Western standards of production or testing other than effectiveness in neutralizing venom and low (ie, current) levels of life-threatening reactions. Good manufacturing processes should be introduced carefully and should be based on proven need and cost-benefit impact on patient care.

\section{Anti snake venom key targets}

Key species should be targeted wherever possible, and polyvalent ASVs effective against all biting species, despite being requested, may not be the ideal solution as a result of their complexity and cost. ${ }^{11}$ For example, $80 \%$ of the fatalities in Africa have been reported to be attributable to the carpet viper (Echis ocellatus). ${ }^{8,14}$ This amounts to some 16000 fatalities per annum. ${ }^{8}$ A simple monovalent whole IgG ASV, developed at low cost, administered to all victims with incoagulable blood, accurately measured with a new, clean, dry, and glass test tube, would be cost effective and would contribute to a significant reduction in mortality in Africa. In the short term, this requirement is paramount and supersedes constantly improving quality and GMP. It makes little sense to be encouraging GMP and various levels of pretesting if no product is currently available and if it has not been possible to arrange a sustainable supply in the past.

\section{Conclusion}

Health care is about resources-it's about the economy. The developing world faces a snakebite problem, and innovative thinking is required to solve this long-standing issue. Developed world standards, thinking, and precepts should not be determining how this problem is resolved. While it might be laudable to provide multispecies, highly purified, and technically advanced ASVs produced under an umbrella of GMPs, it is unlikely to constitute a successful and sustainable strategy in most of the developing world. It is possible to have an effective, low-risk ASV at lower cost. However, that requires an acceptance of market economics and ASV products that better fit developing world economies. It also requires a clear solution, if further time is not to be lost debating why an idealized ASV solution remains unattainable.

The developed world argument and resolution plan has been advanced for nearly 3 decades, and many of the recommendations have remained unresolved or have not been implemented. ${ }^{29}$ Recent deliberations seem to have adopted these same unsuccessful recommendations and have merely repeated them. ${ }^{45}$

Developing world economies have different structures, resources, and priorities. One author argued "The most sophisticated purification procedure is not always necessary to give the best balance between antivenom quality, yield and production cost."12 Eight years and 128000 African Echis victims later, the debate still continues. This paper proposes a potential solution that reconciles the market and the need. The economy and the snakes have something in common; they are not going anywhere! If we are to reduce snakebite mortality, we have to learn to effectively coexist with them both.

\section{References}

1. Warrell DA. Tropical health: venomous bites and stings in the tropical world. Med J Aust. 1993;159:773-779.

2. Warrell DA. Clinical toxicology of snakebite in Asia. In: White J, Meier J, eds. Handbook of Clinical Toxicology of Animal Venoms and Poisons. Boca Raton, FL: CRC Press; 1995:493-593.

3. Muguti G, Maramba A, Washaya CT. Snake bites in Zimbabwe: a clinical study with emphasis on the need for antivenom. Cent Afr J Med. 1994;40:83-88.

4. Wilde H, Thipkong P, Sitprija V, Chaiyabutr N. Heterologous antisera and antivenins are essential biologicals: perspectives on a worldwide crisis. Ann Intern Med. 1996; 125:233-236. 
5. Warrell DA. WHO/SEARO guidelines for the clinical management of snakebite in the Southeast Asian region. SE Asian J Trop Med Public Health. 1999;1:1-85.

6. Cheng AC, Winkel KD. Snakebite and antivenoms in Asia-Pacific: wokabaut wantaim raka hebou ("Walking Together"). Med J Aust. 2001;175:648-651.

7. White J, Warrell DA, Eddleston M, Currie BJ, Whyte IM, Isbister GK. Clinical toxinology-where are we now? $J$ Toxicol Clin Toxicol. 2003;41:263-276.

8. Chippaux JP. Snake Venoms and Envenomations. Florida, FL: Krieger Publishing Company; 2006.

9. Gutierrez JM, Theakston RDG, Warrell DA. Confronting the neglected problem of snakebite envenoming: the need for a global partnership. PLoS Med. 2006;6:e150.DOI:10: 1371/journal.pmed.0030150.

10. Warrell DA. Bites by venomous snakes outside the Americas. In: Auerbach PS, ed. Wilderness Medicine. St. Louis, MO: Mosby; 2007:1086-1123.

11. Stock RP, Massougbodji A, Alagon A, Chippaux JP. Bringing antivenoms to Sub-Saharan Africa. Nature. 2007;25:173-177.

12. Krifi MN, El Ayeb M, Dellagi K. The improvement and standardization of antivenom production in developing countries: comparing antivenom quality, therapeutical efficiency and cost. J Venom Anim Toxins. 1999;5:128-141.

13. Gutierrez JM, Lomonte B, Leon G, Rucavado A, Chaves F, Angulo Y. Trends in snakebite envenomation therapy: scientific, technological and public health considerations. Curr Pharma Des. 2007;13:2935-2950.

14. Laing GD, Lee L, Smith DC, Landon J, Theakston RDG. Experimental assessment of new, low cost antivenom for treatment of carpet viper (Echis ocellatus) envenoming. Toxicon. 1995;33:307-313.

15. Chippaux JP, Lang J, Amadi-Eddine S, Fagot P, Le Mener V. Short report: treatment of snake envenomations by a new polyvalent antivenom composed of highly purified $\mathrm{F}(\mathrm{ab}) 2$ : results of a clinical trial in Northern Cameroon. Am J Med Hyg. 1999;61:1017-1018.

16. Laing GD, Renjifo JM, Ruiz F, et al. A new pan African polyspecific antivenom developed in response to the antivenom crisis in Africa. Toxicon. 2003;42:35-41.

17. Gutiérrez JM, Rojas E, Quesada L, et al. Pan-African polyspecific antivenom produced by caprylic acid purification of horse $\mathrm{IgG}$ : an alternative to the antivenom crisis in Africa. Trans R Soc Trop Med Hyg. 2005;99:468-475.

18. Menou V, White A, Savitz A, Mehrpouya A. Global pharmaceutical sector report. Available at: http://www. ecologyexpress.com/guide/document/innovest_industry_ sample.pdf. Accessed January 14, 2008.

19. Government of Sindh. Anti Snake Venom Laboratory: (Pre Feasibility Report). Karachi: Health Department, Government of Sindh; 2005.

20. Fry BG, Winkel KD, Wickramaratna JC, Hodgson WC, Wuster W. Effectiveness of snake antivenom: species and regional venom variation and its clinical impact. $J$ Toxicol. $2003 ; 22: 23-34$
21. Chippaux JP, Goyffon M. Round table and synthesis of the meeting. Bull Soc Pathol Exot. 2002;95:217-219.

22. Morais V, Massaldi H. Economic evaluation of snake antivenom production in the public system. J Venom Anim Toxins incl Trop Dis. 2006;12:497-511.

23. Simpson ID, Norris RL. Snake antivenom product guidelines in India: the devil is in the details. Wilderness Environ Med. 2007;18:163-168.

24. Phillips RE, Theakston RD, Warrell DA. Paralysis, rhabdomyolysis and haemolysis caused by bites of Russell's viper (Vipera russelli pulchella) in Sri Lanka: failure of Indian (Haffkine) antivenom. Q J Med. 1988;8:691-715.

25. Ariaratnam CA, Sjostrom L, Raziek Z, et al. An open randomised comparative trial of two antivenoms for the treatment of envenoming by Sri Lankan Russell's viper ( $D a$ boia russelii russelii). Trans $R$ Soc Trop Med Hyg. 2001; 95:74-80.

26. Warrell DA. Animal toxins. In: Cook GC, Zumla A, eds. Manson's Tropical Diseases. London, UK: WB Saunders; 2003:581-618.

27. Warrell DA. Injuries, envenoming, poisoning, and allergic reactions caused by animals. In: Warrell DA, Cox TM, Firth JD, eds. Oxford Textbook of Medicine. Oxford: Oxford University Press, Oxford, U.K.; 2003:923-947.

28. Kochar DK, Tanwar PD, Norris RL, et al. Rediscovery of severe saw scaled viper (Echis sochureki) envenoming in the Thar Desert region of Rajasthan, India. Wilderness Environ Med. 2007;18:75-85.

29. World Health Organization. Progress in the characterization of venoms and standardization of antivenoms. WHO Offset Publ. 1981;58:1-44.

30. Malasit P, Warrell DA, Chanthavanich P, et al. Prediction, prevention and mechanism of early (anaphylactic) antivenom reactions in victims of snake bites. BMJ. 1986;292: 17-20.

31. Sampson HA, Mendelson L, Rosen JP. Fatal and near-fatal anaphylactic reactions to food in children and adolescents. N Engl J Med. 1992;327:380-384.

32. Simons FE, Gu X, Simons KJ. Epinephrine absorption in adults: intramuscular versus subcutaneous injection. $J$ Allergy Clin Immunol. 2001;108:871-873.

33. McLean-Tooke APC, Bethune CA, Fay AC, Spickett GP. Adrenaline in the treatment of anaphylaxis: what is the evidence? BMJ. 2003;327:1332-1335.

34. Simpson ID. Snakebite management in India, the first few hours: a guide for primary care physicians. J Indian Med Assoc. 2007;105:324-335.

35. De Silva HJ, Fonseka MMD, Gunatilake SB, Kularatne SAM, Sellahewa KH. Anti-venom for snakebite in Sri Lanka. CMJ. 2002;2:43-45.

36. Cheng AC, Currie BJ. Venomous snakebites worldwide with a focus on the Australia-Pacific region: current management and controversies. J Intensive Care Med. 2004; 19:259-269.

37. Visser LE, Kyei-Faried S, Belcher DW, Geelhoed DW, van Leeuwen JS, van Roosmalen J. Failure of a new antivenom to treat Echis ocellatus snake bite in rural Ghana: the 
importance of quality surveillance. Trans $R$ Soc Trop Med Hyg. 2008; [Epub ahead of print].

38. Simpson ID. The 'worldwide shortage' of anti snake venom: is the only right answer 'produce more' or is it also 'use it smarter'? Wilderness Environ Med. 2008;19:99107.

39. Rojas G, Jiménez JM, Gutiérrez JM. Caprylic acid fractionation of hyperimmune horse plasma: description of a simple procedure for antivenom production. Toxicon. 1994;2:351-363.

40. Otero-Patiño R, Cardoso JL, Higashi HG, et al. A randomized, blinded, comparative trial of one pepsin-digested and two whole $\mathrm{IgG}$ antivenoms for Bothrops snake bites in Uraba, Colombia. Am J Trop Med Hyg. 1998;58:183-189.

41. Otero R, Gutiérrez JM, Rojas G, et al. A randomized blinded clinical trial of two antivenoms, prepared by caprylic acid or ammonium sulphate fractionation of $\mathrm{IgG}$, in
Bothrops and Porthidium snake bites in Colombia: correlation between safety and biochemical characteristics of antivenoms. Toxicon. 1999;37:895-908.

42. Otero R, León G, Gutiérrez JM, et al. Efficacy and safety of two whole $\operatorname{IgG}$ polyvalent antivenoms, refined by caprylic acid fractionation with or without beta-propiolactone, in the treatment of Bothrops asper bites in Colombia. Trans R Soc Trop Med Hyg. 2006;100:1173-1182.

43. Dart RC, McNally J. Efficacy, safety, and use of snake antivenoms in the United States. Ann Emerg Med. 2001; 37:181-188.

44. Ruha AM, Curry SC, Beuhler M, et al. Initial postmarketing experience with Crotalidae polyvalent immune Fab for treatment of rattlesnake envenomation. Ann Emerg Med. 2002;39:609-615.

45. World Health Organization. Rabies and Envenomings: A Neglected Public Health Issue. Geneva, Switzerland: World Health Organization; 2007. 